RU Маркеры снижения эпистемической ответственности в немецком научно-популярном дискурсе: лексико-синтаксический уровень

\author{
Чепурная А. И.
}

Аннотация. Цель исследования - охарактеризовать лексико-синтаксические маркеры снижения эпистемической ответственности в немецком научно-популярном дискурсе. В статье раскрывается содержание понятия эпистемической ответственности и анализируются лексико-синтаксические маркеры ее снижения. Научная новизна исследования заключается в описании языковых маркеров снижения эпистемической ответственности в дискурсе научно-популярного жанра. В результате показано, что основными лексико-синтаксическими средствами снижения эпистемической ответственности в исследуемом материале являются эпистемические наречия, конструкции с путативными глаголами, модальные глаголы и двойной союз entweder... oder.

\title{
EN Markers of Reducing Epistemic Responsibility in German Popular Science Discourse: Lexical-Syntactic Level
}

\author{
Chepurnaya A. I.
}

\begin{abstract}
The research aims to characterise lexical and syntactic markers of reducing epistemic responsibility in German popular science discourse. The article sheds light on the content of the concept of epistemic responsibility and analyses lexical and syntactic markers of its reduction. Scientific novelty of the research lies in describing linguistic markers of reducing epistemic responsibility in the discourse of the popular science genre. As a result, it is shown that the main lexical and syntactic means of reducing epistemic responsibility in the studied material are epistemic adverbs, constructions with putative verbs, modal verbs and the two-part conjunction entweder... oder.
\end{abstract}

\section{Введение}

Проблема языкового маркирования эпистемической ответственности в настоящее время вызывает значительный интерес исследователей, ее актуальность особенно возросла в связи с развитием лингвоэкспертной деятельности. Кроме вклада в решение задач лингвоэкспертологии, исследование языковых маркеров эпистемической ответственности позволяет расширить и обогатить теорию модальности и эвиденциальности. Актуальность изучения языковой реализации эпистемической ответственности в научно-популярном дискурсе обусловлена значимой общественной ролью этого жанра дискурса, призванного популяризировать достижения науки [3, с. 43].

Цель исследования достигалась путем решения следующих задач: во-первых, уточнить содержание понятия эпистемической ответственности; во-вторых, выявить и описать лексико-синтаксические маркеры ее снижения в научно-популярном дискурсе.

Исследование выполнено с применением методов контент-анализа и лексикографического описания на материале Мангеймского корпуса немецкого языка Deutsches Referenzkorpus (DeReKo). В качестве непосредственного материала для анализа был использован подкорпус Zeit Wissen, в котором собраны тексты одноименного научно-популярного журнала.

Теоретическая база настоящего исследования представлена трудами А. В. Зеленщикова [4], В. 3. Панфилова [7] и А. В. Авериной [1], посвященными вопросу эпистемической модальности, а также исследованиями категории эвиденциальности, выполненными Н. А. Козинцевой [6], Б. Вимером [14] и Р. Д. Шакировой [9].

Научная статья (original research article) | https://doi.org/10.30853/phil210243

(c) 2021 Авторы. ООО Издательство «Грамота» ( 2021 The Authors. GRAMOTA Publishers). Открытый доступ предоставляется на условиях лицензии СС BY 4.0 (open access article under the CC BY 4.0 license): https://creativecommons.org/licenses/by/4.0/ 
Кроме того, методология настоящего исследования опирается на работы М. Карретеро и Ж. Р. ЗамораноМансилла, в которых отмечается связь категорий эвиденциальности и эпистемической модальности с выражением ответственности говорящего за достоверность передаваемой информации [10].

Практическая значимость исследования видится в возможности использования результатов при разработке учебных курсов по лексической семантике, стилистике и прагматике, а также спецкурсов по лингвистической экспертизе.

\section{Понятие эпистемической ответственности}

Эпистемическая ответственность может быть охарактеризована как категория метакогнитивного уровня [5], поскольку, представляя собой ответственность за достоверность пропозиционального содержания высказывания [8, с. 12], коррелирует со знанием субъекта о своем собственном знании. К отмеченным исследователями средствам выражения эпистемической ответственности на языковом уровне относятся категории эпистемической модальности и эвиденциальности [8; 10].

Согласно концепции, разработанной нами в рамках диссертационного исследования [8], языковые экспликаторы эпистемической ответственности делятся на три группы: маркирующие высокую степень эпистемической ответственности, снижение и уход от нее. К первой группе относятся маркеры со значением фактивности, категорической достоверности и инференциальной уверенности; вторая группа включает средства, выражающие значение путативности, проблематической достоверности, инференциальной возможности или вероятности; третья группа объединяет маркеры с репортативно-эвиденциальной семантикой.

\section{Маркеры снижения эпистемической ответственности}

\section{Эпистемические наречия}

Репрезентативным средством снижения эпистемической ответственности в проанализированном корпусе фрагментов научно-популярного дискурса являются эпистемические наречия (суммарное число вхождений - 2151), которые представляется возможным разделить на три группы на основании их лексикографических описаний [12]:

- $\quad$ наречия, придающие высказыванию модус предположения с опорой на доступные для наблюдения факты, внешние проявления ситуации: offenbar, offensichtlich, anscheinend:

(1) Psychische Zustände spiegeln sich im Körper wider, aber ebenso beeinflusst die Körperhaltung anscheinend auch die Psyche. Mit welcher Körperhaltung wir durchs Leben gehen, ist eine Frage der Einstellung - und umgekehrt (ZWI18/JUN.00015 Zeit Wissen, 12.06.2018, S. 62; Geht so) [11]. / Психические состояния оказывают влияние на физическое состояние организма, но положение тела также, по-видимому, влияет на психику. Психологическая установка определяет, с какой осанкой мы идем по жизни, - и наоборот (здесь и далее перевод автора статьи. - А. Ч.);

- $\quad$ наречия с семантикой возможности $(\mathrm{p}=$ не р): möglicherweise, womöglich, vielleicht, eventuell. 3начение возможности не сопряжено с выражением говорящим эпистемических предпочтений, вследствие чего р и не р могут рассматриваться как равновероятные:

(2) Möglicherweise hat die Evolution auf für sie typische Weise ein bereits vorhandenes System für neue Aufgaben umgenutzt: zum Speichern und Abrufen von Information (ZWI19/JUN.00009 Zeit Wissen, 18.06.2019, S. 20; Umschalten!) [Ibidem]. / Возможно, эволюция типичным для нее образом приспособила существующую систему к решению новых задач: хранению и извлечению информации;

- $\quad$ наречия со значением вероятности ( $>$ не p): wahrscheinlich, vermutlich. Значение вероятности характеризуется большей эпистемической силой, чем значение возможности, что выражается формулой $p>$ не $p$, означающей наличие у говорящего эпистемических предпочтений в пользу р. В примере (3) с помощью наречия wahrscheinlich говорящий выражает предположение «со значительной уверенностью» [12]:

(3) In der Westantarktis ist der Zerfall des Eisschilds wahrscheinlich nicht mehr zu verhindern, aber andere Kipppunkte liegen noch vor uns (ZWI19/FEB.00022 Zeit Wissen, 12.02.2019, S. 92; 9 Ideen, geboren aus der Hoffnung) [11]. / Разрушение Западно-Антарктического ледяного щита, вероятно, уже не предотвратить, но другие критические точки еще не пройдены.

Примеры (1), (2) и (3) демонстрируют снижение говорящим эпистемической ответственности за счет употребления наречий, выражающих модальное значение проблематической достоверности, характеризующееся неоднородным семантическим наполнением. Наиболее эпистемически сильным в группе значений проблематической достоверности представляется значение вероятности.

\section{Конструкции с путативными глаголами}

Снижение степени эпистемической ответственности возможно с помощью путативных глаголов meinen, vermuten, glauben, denken, а также глагола scheinen, сочетающего путативную и перцептивную семантику (ср. с русскоязычным семантическим аналогом казаться [2, с. 119, 381, 384]). 
В проанализированном корпусе выявлены случаи функционирования глаголов meinen, vermuten, glauben, denken в конструкциях с вводной функцией (4) и в главной части сложноподчиненного предложения в сочетании с субъектом, кореферентным автору текста (5):

(4) Er, denke ich, kennt sich sicher aus mit den Hürden und Versuchungen des Lebens, aus eigener Erfahrung und der Erfahrung als Seelsorger (ZWI19/OKT.00010 Zeit Wissen, 15.10.2019, S. 22; Wie gesund ist die Sünde?) [11]. / Он, я думаю, наверняка хорошо знает об испытаниях и искушениях на жизненном пути как по собственному опыту, так и опыту пастырства;

(5) Ich vermute, dass Menschen in früheren Zeiten eine engere Verbindung zur Natur hatten, in der sie lebten, oder zu ihrer Sippe. Ich glaube, dass das Ego über die Zeit immer stärker wurde (ZWI19/OKT.00013 Zeit Wissen, 15.10.2019, S. 34; “Ich hatte Spiritualität völlig missverstanden”) [Ibidem]. / Я предполагаю, что в прежние времена люди имели более тесную связь с окружающей их природой или со своим родом. Я считаю, что со временем человеческое Я становилось все сильнее.

Главная часть сложноподчиненного предложения с путативным глаголом образует модальную рамку по отношению к диктуму придаточной части, снижая эпистемическую силу высказывания за счет выражения значения проблематической достоверности, и маркирует низкую степень принятия на себя автором эпистемической ответственности.

Путативный глагол scheinen характеризуется широкими сочетаемостными возможностями и способностью употребления в синтаксических структурах разного типа:

- в конструкции scheinen + zu + Infinitiv:

(6) Alarmrufe zu erzeugen scheint bei den meisten Primatenarten genetisch fixiert zu sein (ZWI19/FEB.00020 Zeit Wissen, 12.02.2019, S. 80; Das! Läuft! Schief!) [Ibidem]. / У большинства видов приматов подача сигналов тревоги, кажется, заложена генетически;

- в сочетании с прилагательным:

(7) Im Falle des Einkaufens im Internet scheinen die Vorteile klar: Die Geschäfte sind stets verfügbar, die Schaufenster immer gefüllt, und die Preise stehen in großer Konkurrenz (ZWI14/FEB.00029 Zeit Wissen, 18.02.2014, S. 84; Heute: Einkaufen) [Ibidem]. / В случае покупок в Интернете преимущества кажутся очевидными: магазины всегда доступны, витрины всегда полны, а цены сильно конкурируют;

- в сочетании с причастием I или II:

(8) Die Ergebnisse der Experimente scheinen vielversprechend (ZWI18/JUN.00011 Zeit Wissen, 12.06.2018, S. 42; Gesund im Urlaub) [Ibidem]. / Результаты экспериментов кажутся многообещающими;

- в составе главной части сложноподчиненного предложения, управляющей придаточным изъяснительным:

(9) Es scheint, als verrate der Gang etwas über unsere körperliche Verwundbarkeit (ZWI18/JUN.00015 Zeit Wissen, 12.06.2018, S. 62; Geht so) [Ibidem]. / Кажется, походка выдает нашу физическую уязвимость.

Актуализация характерного для глагола scheinen компонента значения «производить определенное впечатление» [12] в примерах (6), (7), (8), (9) придает высказыванию модус проблематической достоверности, снижая его эпистемическую силу.

\section{Модальные глаголы}

Как отмечает А. В. Зеленщиков, наиболее значимым в семантической структуре модальных глаголов выступает противопоставление деонтической и эпистемической семантики [4, с. 105-106]. Анализ контекстов употребления модальных глаголов в корпусе текстов немецкого научно-популярного дискурса показал, что однозначное определение актуализируемой в конкретном контексте семантической грани нередко является невозможным. Более того, в одном контексте могут сочетаться несколько семантических аспектов, что существенно затрудняет количественный анализ модальных глаголов как маркеров снижения эпистемической ответственности, которыми они могут выступать в случае эпистемического прочтения.

Модальные глаголы характеризуются выражением разной степени уверенности говорящего в достоверности сообщаемого. Так, согласно точке зрения Г. Цыбатова, müssen придает высказыванию модус эпистемически сильного предположения, граничащего с уверенностью, глаголу dürfen свойственна семантика вероятности, а mögen и können выражают значение возможности [15, S. 67-68]. Г. Фриц предложил шкалу тӧgen/ können/dürfen/werden/müssen, на которой расположил модальные глаголы немецкого языка в порядке возрастания эпистемической силы, но отметил при этом, что положение на шкале глаголов mögen, können, dürfen не является прочным, что обусловлено сложностью определения семантических различий между ними в эпистемическом прочтении [13, S. 47]:

(10) Mein Weg zu einem Tee-Snob begann in einem Geschäft in der Hamburger Innenstadt, drei Jahre muss das jetzt her sein (ZWI19/APR.00023 Zeit Wissen, 16.04.2019, S. 92; Ansichten eines Tee-Snobs) [11]. / Мой путь к тому, чтобы стать чайным снобом, начался в магазине в центре Гамбурга, с тех пор прошло уже, должно быть, три года;

(11) Zwar waren auch die Neandertaler keine Einzelgänger, sie konnten wahrscheinlich miteinander sprechen und jagen. Aber ihre Kooperationsfähigkeit dürfte eher bescheiden gewesen sein (ZWI17/APR.00010 Zeit Wissen, 25.04.2017, S. 28; Die Pfade der Erkenntnis) [Ibidem]. / Хотя и неандертальцы тоже жили не в одиночестве; они, вероятно, могли разговаривать друг с другом и охотиться группами. Но их способность к кооперации, вероятнее всего, была скромной; 
(12) Wer etwa nachts häufig aus großer Höhe hinunterfällt und panische Angst vor dem Aufschlag hat, könnte unter Kontrollverlust leiden oder von Versagensängsten geplagt werden (ZWI19/FEB.00005 Zeit Wissen, 12.02.2019, S. 10; 3. Was verraten unsere Träume über uns?) [Ibidem]. / Тот, кто во сне часто падает с большой высоты и испытывает при этом панический страх, может быть склонен к потере контроля над собой или страдать от боязни неудач.

В примерах (10), (11) и (12) модальные глаголы müssen, dürfen и können, употребленные в эпистемическом прочтении, маркируют снижение эпистемической ответственности за счет выражения значения проблематической достоверности. В примере (10) значение уверенного предположения, выраженного с помощью тӥssen, подчеркивается употреблением глагола в изъявительном наклонении, тогда как в примерах (11) и (12) глаголы dürfen и können, выражающие эпистемически менее сильные значения вероятности и возможности соответственно, употреблены в форме конъюнктива II.

\section{Двойной союз еntweder... oder}

Семантика проблематической достоверности может быть выражена с помощью двойного союза entweder... oder:

(13) Wenn sich aus solchen Verhaltensweisen ein Bewusstsein deduzieren lässt, so kann das zweierlei bedeuten: Entweder hat sich das Bewusstsein im Laufe der Evolution auf mindestens zwei verschiedene Weisen entwickelt, oder es hat sich herausgebildet, bevor Vögel und Säugetiere verschiedene evolutionäre Wege gingen (ZWI19/JUN.00015 Zeit Wissen, 18.06.2019, S. 58; Was weiß der Rabe?) [Ibidem]. / Если на основании такого поведения может быть сделан вывод о наличии сознания, это может означать следующее: либо эволюционное развитие сознания происходило как минимум двумя различными способами, либо оно возникло до того, как птицы и млекопитающие пошли разными эволюционными путями.

В примере (13) с помощью союза entweder... oder автор вводит в рассмотрение два взаимоисключающих сценария со статусом предположения, которые представляются как равновероятные.

\section{Заключение}

В результате проведенного исследования могут быть сформулированы следующие выводы. Во-первых, эпистемическая ответственность как ответственность за достоверность передаваемой информации относится к категориям метакогнитивного уровня и вербализуется через категории эпистемической модальности и эвиденциальности.

Во-вторых, лексико-синтаксическими маркерами снижения эпистемической ответственности в немецком научно-популярном дискурсе выступают эпистемические наречия с семантикой проблематической достоверности (offenbar, offensichtlich, anscheinend, möglicherweise, womöglich, vielleicht, eventuell, wahrscheinlich, vermutlich), двойной союз (entweder... oder), путативные (meinen, vermuten, glauben, denken, scheinen) и модальные (könпеn, dürfen, mögen, müssen) глаголы, придающие высказыванию модус проблематической достоверности, инференциальной возможности или вероятности. В качестве наиболее частотных средств, маркирующих снижение эпистемической ответственности, в проанализированном корпусе могут быть выделены эпистемические наречия.

Перспективы дальнейшего изучения обозначенной в настоящем исследовании проблемы видятся в уточнении репертуара средств маркирования эпистемической ответственности за счет расширения материала, привлекаемого к анализу.

\section{Источники | References}

1. Аверина А. В. Эвиденциальность и эпистемическая модальность в семантике частиц и их сочетаемость с модальными словами (на материале немецких модальных частиц wohl, doch и ја) // Филологические науки. Вопросы теории и практики. 2016. № 4 (58). Ч. 3. С. 64-68.

2. Апресян Ю. Д. Избранные труды: в 2-х т. М.: Школа «Языки русской культуры», 1995. Т. 2. Интегральное описание языка и системная лексикография. 767 с.

3. Егорова Л. А. К вопросу об определении понятия «научно-популярный дискурс» // Вестник Российского университета дружбы народов. Серия «Русский и иностранные языки и методика их преподавания». 2009. № 1. С. 42-46.

4. Зеленщиков А. В. Пропозиция и модальность. Изд-е 2-е, доп. М.: Кн. дом «Либроком», 2010. 216 с.

5. Каралашвили Н. Г. Отдельные аспекты выражения эпистемической ответственности в интернет-дискурсе // Studia Linguistica (Санкт-Петербург). 2019. № 28. С. 189-190.

6. Козинцева Н. А. Категория эвиденциальности (проблемы типологического анализа) // Вопросы языкознания. 1994. № 3. С. 92-104.

7. Панфилов В. З. Категория модальности и ее роль в конструировании структуры предложения и суждения // Вопросы языкознания. 1977. № 4. С. 37-48.

8. Чепурная А. И. Языковое маркирование эпистемической ответственности автора публицистического текста: дисс. ... к. филол. н. Ставрополь, 2015. 177 с.

9. Шакирова Р. Д. Инференциальная эвиденциальность и ее разновидности в современном немецком языке // Вестник Вятского государственного гуманитарного университета. 2010. № 2: в 4-х ч. Ч. 2. С. 89-93. 
10. Carretero M., Zamorano-Mansilla J. R. Annotating English adverbials for the categories of epistemic modality and evidentiality // English Modality: Core, Periphery and Evidentiality / ed. by J. I. Marín-Arrese, M. Carretero, J. Arús Hita, J. van der Auwera. Berlin - Boston: DE GRUYTER, 2013. P. 317-355.

11. Deutsches Referenzkorpus (DeReKo) [Электронный ресурc]. URL: https://cosmas2.ids-mannheim.de/cosmas2-web/ (дата обращения: 13.03.2021).

12. Duden online [Электронный ресурc]. URL: https://www.duden.de/ (дата обращения: 24.03.2021).

13. Fritz G. Deutsche Modalverben 1609 - Epistemische Verwendungsweisen. Ein Beitrag zur Bedeutungsgeschichte der Modalverben im Deutschen // Beiträge zur Geschichte der deutschen Sprache und Literatur. 1991. Bd. 113. S. 28-52.

14. Wiemer B. Particles, Parentheticals, Conjunctions and Prepositions as Evidentiality Markers in Contemporary Polish (A First Exploratory Study) // Studies in Polish Linguistics. 2006. Vol. 3. P. 5-67.

15. Zybatow G. Die deutschen Modalverben in epistemischem Gebrauch und ihre Wiedergabe im Russischen // Zeitschrift für Slawistik. 2013. Bd. 31. Teil 1. S. 67-74.

\section{Информация об авторах | Author information}

RU Чепурная Алена Ивановна ${ }^{1}$, к. филол. н., доц.

${ }^{1}$ Ставропольский государственный аграрный университет

EN Chepurnaya Alena Ivanovna ${ }^{1}, \mathrm{PhD}$

${ }^{1}$ Stavropol State Agrarian University

${ }^{1}$ alena-chep@mail.ru

\section{Информация о статье | About this article}

Дата поступления рукописи (received): 07.04.2021; опубликовано (published): 31.05.2021.

Ключевые слова (keywords): научно-популярный дискурс; эвиденциальность; эпистемическая модальность; эпистемическая ответственность; popular science discourse; evidentiality; epistemic modality; epistemic responsibility. 